\title{
Chordal translocation for ischemic mitral regurgitation may ameliorate tethering of the posterior and anterior mitral leaflets
}

Shinji Masuyama, MD, ${ }^{a}$ Akira Marui, MD, PhD, ${ }^{a}$ Takeshi Shimamoto, MD, ${ }^{a}$ Michihito Nonaka, MD, ${ }^{a}$ Miwako Tsukiji, MD, ${ }^{b}$ Nozomi Watanabe, MD, PhD, ${ }^{\mathrm{b}}$ Tadashi Ikeda, MD, PhD, ${ }^{\mathrm{a}}$ Kiyoshi Yoshida, MD, PhD, ${ }^{\mathrm{b}}$ and Masashi Komeda, MD, PhD ${ }^{\mathrm{a}}$

Objective: Treatment of ischemic mitral regurgitation accompanied by strong tethering remains a challenge. Undersized ring annuloplasty is frequently associated with residual/recurrent mitral regurgitation caused by mitral-leaflet tethering. Although chordal cutting is a simple procedure for repairing severe tethering of the anterior mitral leaflet, it often affects mitral valvular-ventricular continuity. In this study, using 3dimensional echocardiography, we investigated the effects of "chordal translocation" on the geometry of the mitral components in a canine model of acute ischemic mitral regurgitation.

Methods: In 6 mongrel dogs, under cardiopulmonary bypass with cardiac arrest, artificial chordae were implanted to each papillary-muscle tip and passed through the midseptal annulus to an external tourniquet to control the tension of the stitch thereafter. Subsequently, secondary chordae were cut near their point of attachment to the anterior leaflet. After weaning from cardiopulmonary bypass, acute ischemic mitral regurgitation was induced by ligating the obtuse marginal branches. We obtained data in 2 states of the artificial chordae: relaxation (simulating chordal cutting) and gentle traction (simulating chordal translocation).

Results: In the chordal translocation state versus the chordal cutting state, the left ventricle ejection fraction $(42.6 \% \pm 2.9 \%$ vs $33.2 \% \pm 2.3 \%, P<.0001)$, preload recruitable stroke work $(54.8 \pm 2.7 \mathrm{~mm} \mathrm{Hg}$ vs $34.1 \pm 2.2 \mathrm{~mm} \mathrm{Hg}, P=.0002)$, and end-systolic elastance $(6.7 \pm 0.5 \mathrm{~mm} \mathrm{Hg} / \mathrm{mL}$ vs $4.2 \pm 0.2 \mathrm{~mm} \mathrm{Hg} / \mathrm{mL}, P=.0013)$ improved markedly. The mitral-valve tethering volume, defined as the volume enclosed by the mitral annulus and 2 leaflets, was smaller in the chordal translocation state than in the chordal cutting state $\left(812 \pm 88 \mathrm{~mm}^{3}\right.$ vs $\left.1213 \pm 41 \mathrm{~mm}^{3}, P=.03\right)$. In the chordal translocation state (CT-1 and CT-2) versus the chordal cutting state, the posterior mitral-leaflet tethering area $\left(15.7 \pm 0.7 \mathrm{~mm}^{2}\right.$ vs $25.1 \pm 1.2 \mathrm{~mm}^{2}, P<.0001$

From the Department of Cardiovascular Surgery, Kyoto University Graduate School of Medicine, ${ }^{\mathrm{a}}$ Kyoto, Japan; and Department of Cardiology, Kawasaki Medical School, ${ }^{\text {b }}$ Kurashiki, Japan.

Received for publication Oct 18, 2007; revisions received May 2, 2008; accepted for publication June 15, 2008.

Address for reprints: Masashi Komeda, MD, $\mathrm{PhD}$, Department of Cardiovascular Surgery, Kyoto University Graduate School of Medicine, 54 Shogoin-Kawahara, Sakyo, Kyoto 606-8507, Japan (E-mail: komelab@ kuhp.kyoto-u.ac.jp).

J Thorac Cardiovasc Surg 2008;136:868-75 0022-5223/\$34.00

Copyright (C) 2008 by The American Association for Thoracic Surgery

doi:10.1016/j.jtcvs.2008.06.034 for CT-1 and $15.0 \pm 0.7 \mathrm{~mm}^{2}$ vs $25.1 \pm 1.2 \mathrm{~mm}^{2}, P<.0001$ for CT-2) showed a greater improvement than the anterior mitral-leaflet tethering area $\left(41.0 \pm 0.7 \mathrm{~mm}^{2}\right.$ vs $46.1 \pm$ $1.3 \mathrm{~mm}^{2}$ for CT- $1, P=.01$ and $812 \pm 88 \mathrm{~mm}^{2}$ vs $1213 \pm 41 \mathrm{~mm}^{2}$ for CT-2, $P=.03$ ). The mitral annular geometry did not differ between the states.

Conclusion: Compared with chordal cutting alone, chordal translocation improved both the left ventricle function and mitral geometry in a canine model of acute ischemic mitral regurgitation. Chordal translocation may be beneficial because it ameliorates the tethering of both the anterior and posterior leaflets, which is aggravated by mitral annuloplasty alone.

$\mathrm{I}$ schemic mitral regurgitation (IMR) is a severe complication arising after myocardial infarction and is associated with excessive mortality, independently of the underlying condition of left ventricular (LV) dysfunction. ${ }^{1-4}$ Despite considerable progress in the field of cardiac surgery, surgical treatment of IMR currently remains a challenge for surgeons. Undersized ring annuloplasty has gained popularity. 

Abbreviations and Acronyms
$\mathrm{AML}=$ anterior mitral leaflet
$\mathrm{CC}=$ chordal cutting
$\mathrm{CPB}=$ cardiopulmonary bypass
$\mathrm{CT}=$ chordal translocation
Ees = end-systolic elastance
IMR = ischemic mitral regurgitation
$\mathrm{LV}=$ left ventricular
LVEF = left ventricular ejection fraction
MR = mitral regurgitation
$\mathrm{PM}=$ papillary muscle
PML = posterior mitral leaflet
PPM = posterior papillary muscle
PRSW $=$ preload recruitable stroke work
3D $=3$-dimensional

However, this procedure may have various outcomes, and it is frequently associated with residual/recurrent mitral regurgitation (MR). ${ }^{5-7}$

The chordal cutting (CC) procedure, which involves disruption of the secondary chordae, is a simple method performed to repair severe tethering. ${ }^{8}$ Some authors reported that this method could improve leaflet coaptation and that it did not adversely affect LV function in an animal model. ${ }^{9,10}$ However, the secondary chordae maintain mitral valvularventricular continuity, which plays an important role in LV structure and function. ${ }^{11}$ Thus, the $\mathrm{CC}$ method may reduce anterior leaflet tethering and mitral valve regurgitation at the cost of the LV systolic geometry or function.

We previously reported an improvement in the LV function after chordal translocation (CT) (ie, CC accompanied by restoration of continuity between the papillary tips and the anterior mitral annulus by using artificial chordae) in a normal canine model. ${ }^{12}$ Although this technique has been shown to improve LV function after CC, details of the geometric changes it induces in the mitral valve components, particularly in the mitral-valve leaflet and annulus in the IMR model, remain unknown.

In the present study, we investigated the effects of the CT technique with regard to the geometry of the mitral valve components by performing real-time 3-dimensional (3D) echocardiography in a canine model of acute IMR.

\section{Materials and Methods}

\section{Surgical Preparation}

Six mongrel dogs (weight, $18.2 \pm 0.8 \mathrm{~kg}$ ) were premedicated with ketamine hydrochloride $(20 \mathrm{mg} / \mathrm{kg}$ administered intramuscularly), and general anesthesia was induced with propofol $\left(1-3 \mathrm{mg} / \mathrm{kg}^{-1}\right.$ / $\mathrm{h}^{-1}$ administered intravenously). Anesthesia was maintained by inhalation of isoflurane $(0.5 \%-1.5 \%)$.

The dogs were placed in the right lateral decubitus position, and a left anterior thoracotomy was performed through the fifth intercostal space. The pericardium was opened, and the heart was suspended in a cradle.
A rubber catheter, used as an inferior vena cava occluder, was placed around the inferior vena cava to provide transient preload reduction.

Under cardiopulmonary bypass (CPB), the ascending aorta was crossclamped, and antegrade crystalloid cardioplegia was injected. Left atriotomy was performed via the appendage; for CT, artificial chordae of 4-0 polypropylene sutures were placed on the tip of each papillary muscle (PM), which represents the origin of the secondary chordae, and were put through the midseptal annulus (ie, the saddle horn) to an external tourniquet to ensure the smooth movement of the suture. Damage to the aortic valve, especially the noncoronary cusp, is potentially a major concern. We paid attention not to injure aortic valves, and no damage was noted at autopsy. This process is shown in Figure 1. The length of the artificial chordae for CT was determined under the "taut" condition, which has been described. ${ }^{12}$ The natural secondary chordae were cut near the point of attachment to the anterior leaflet. The secondary chordae were clearly identified by turning over the anterior leaflet.

The left atrium was subsequently closed, and the tourniquets were taken out of the left atrium to control the artificial chordal length/tension thereafter. The dogs were weaned from CPB, and polypropylene 4-0 sutures were then passed around the second and third obtuse marginal branches of the left circumflex coronary artery to induce the posterior LV wall ischemia thereafter.

\section{Experimental Protocol}

After the dogs were weaned from CPB, the hemodynamic state was stabilized. Inotropic agents were not used during the weaning process. The dogs were studied in the right lateral decubitus position with the chest open, and anesthesia was maintained with isoflurane $\left(0.5 \%-1.5 \%\right.$ via inhalation) and propofol $\left(1-3 \mathrm{mg} / \mathrm{kg}^{-1} / \mathrm{h}^{-1}\right.$ administered intravenously).

In regard to the anatomy, the release of the artificial chordae represented the $\mathrm{CC}$ state, and gentle traction of the artificial chordae in the taut condition represented the CT state. The length of the artificial chordae was controlled during each state.

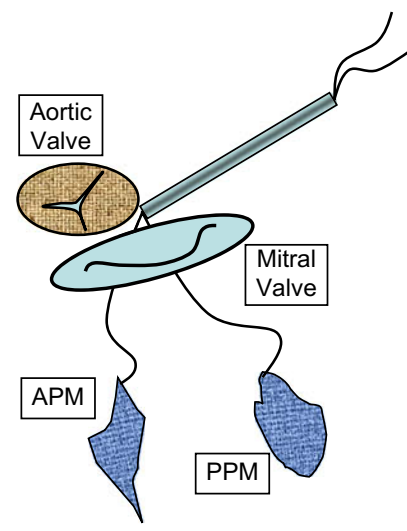

Chordal cutting (CC)

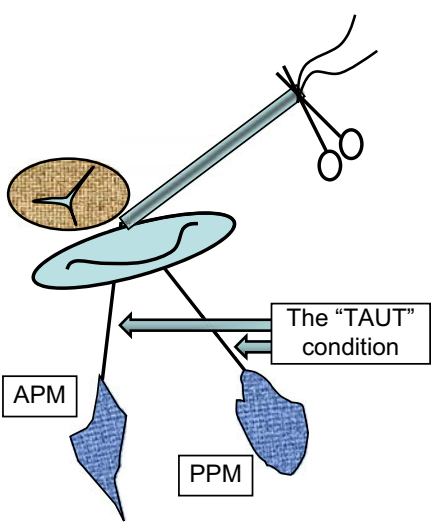

Chordal translocation (CT)
Figure 1. Schematic representation of CC and CT. "CT sutures" were implanted by anchoring 4-0 polypropylene sutures to each PM tip, which represents the origin of the secondary chordae, and through the midseptal annulus (saddle horn) to an external tourniquet to ensure the smooth movement of the suture. APM, Anterior papillary muscle; PPM, posterior papillary muscle. 


\section{Induction of Myocardial Ischemia}

We evaluated the data obtained after weaning from $\mathrm{CPB}$ with $\mathrm{CT}$, described as the post-CPB state. Subsequently, lidocaine $(40 \mathrm{mg}$ ) was infused 5 minutes before placement of the coronary snares. An epinephrine drip was titrated to maintain the coronary perfusion pressure, and the coronary snares were subsequently ligated to induce ischemia of the LV posterior and lateral walls, as reported previously. ${ }^{13}$ Ventricular arrhythmias were treated by using lidocaine (40-100 mg) as required. The condition of the animals then stabilized, and they recovered from ischemia within 20 minutes. The posterior and lateral wall motion worsened within 30 minutes, after which epinephrine administration was reduced and eventually terminated.

The condition 60 minutes after coronary ischemia was defined as the CT-1 state. Subsequently, the artificial chordae were relaxed to represent the $\mathrm{CC}$ state. Finally, gentle traction was applied again to the artificial chordae in the taut condition to simulate the CT state again (CT-2 state), to avoid the misleading data caused by the time-course change of the animal condition. During the acquisition of hemodynamic and echocardiography data, ventilation was briefly arrested at end expiration to prevent respiratory influences. We evaluated the data obtained in each state: post-CPB, CT-1, CC, and CT-2.

\section{Data Acquisition}

In this experiment in which we performed repeated pulling and releasing, a stable vital condition was indispensable. Data were measured after achieving a stable vital condition, and this required 3 -minute intervals. Moreover, the data were acquired 3 times (every 3 minutes), and the values obtained are believed to be constant because they are the average values.

\section{Left Ventricular Function and Volume}

Arterial pressure was measured at the right femoral artery. Electrocardiographic monitoring was performed, and a multilumen catheter (7.5F, Baxter Healthcare, Irvine, Calif) was inserted into the right jugular vein and positioned in the pulmonary artery to measure the pulmonary artery pressure.

A micromanometer-tipped catheter (Miller MPC-500, Miller Instruments Inc, Houston, Tex), which was used to monitor the LV pressure, and a 6-F conductance catheter (2S-RH6DA-116, Alpha Medical Instruments Inc, Mission Viejo, Calif), which was used to monitor the LV volume, were inserted through the LV apex.

The hemodynamic and geometric parameters measured were as follows: heart rate, LV end-systolic pressure, LV end-diastolic pressure, maximum positive rate of change of the LV pressure $(\mathrm{dP} /$ $\left.\mathrm{dt}_{\max }\right)$, minimum negative rate of change of the LV pressure $(\mathrm{dP} /$ $\mathrm{dt}_{\text {min }}$ ), time constant (Tau), LV ejection fraction (LVEF), LV endsystolic volume, and LV end-diastolic volume. The end-systolic elastance (Ees) and preload recruitable stroke work (PRSW) were calculated to assess the global LV systolic function. The Ees and PRSW were calculated for 8 consecutive beats along the midslope of the end-systolic pressure-volume relation curve.

\section{Echocardiography}

Data were acquired by using the SONOS 7500 system (Philips U1trasound, Bothell, Wash) for 3D studies. Some data, including the MR grade and the tethering area and depth of the mitral leaflet were acquired with a Vivid 7 system (GE Medical System, Milwau- kee, Wis) for 2-dimensional studies. We used the novel 3D computer software Real View (YD Ltd, Osaka, Japan) to analyze the data obtained in the 3D studies. As previously reported, ${ }^{14}$ the $3 \mathrm{D}$ data were automatically cropped into 18 radial planes oriented 10 degrees apart. The mitral annulus in each cropped plane at midsystole was marked manually, while the mitral leaflets were traced semiautomatically. The tips of the PMs were obtained on the cropped planes and marked. On the basis of these data, 3D images of the mitral leaflets and annulus were reconstructed. The position of the tips of each PM was identified in the 3D data. The 3D images show the configuration of the leaflet curvature using surface colorations and curved annulus rings, with an alignment of PM tips. The images can be rotated and observed from any direction. To assess the geometric changes in the mitral annulus, annular area, and annular circumference, the distance between the septal and lateral site of the mitral annulus (S-P dimension), and the distance between the commissures in the mitral annulus (C-C dimension) were directly calculated from the 3D images.

The tethering volume was calculated as the volume enclosed between the annular plane and mitral leaflets. To observe the shift in PM position, we measured the distance between the tip of each PM and the saddle horn (anterior/posterior PM-annulus distance), the distance between the tips of the PMs (PM distance), the angle formed by the 2 lines connecting the saddle horn to the tip of each PM (interpapillary angle), and the triangular area between the saddle horn and each PM tip (PM-annulus area) (Figure 2).

The study protocol was approved by the Kyoto University Ethics Committee for Animal Research. All animals received humane care in compliance with the guidelines prescribed in the Principles of Laboratory Animal Care, formulated by the National Society for Medical Research, and the Guide for the Care and Use of

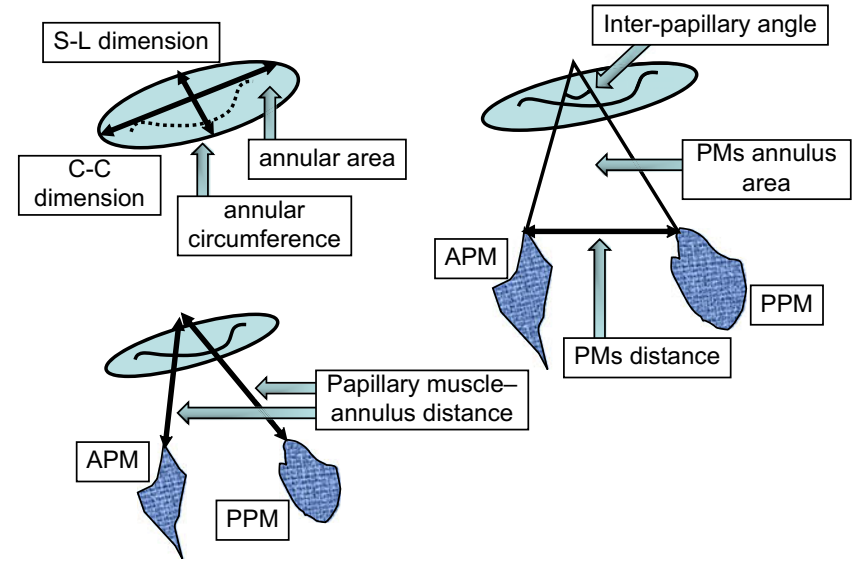

Figure 2. Images of mitral apparatus on echocardiography. Annular area: area of the mitral annulus. S-L dimension: distance between the septal and lateral site of the mitral annulus. C-C dimension: distance between commeasures in the mitral annulus. Anterior/posterior PM-annulus distance: distance between the tips of anterior/posterior PM and the saddle horn. PM distance: distance between the tips of the PMs. Interpapillary angle: angle formed between the 2 lines connecting the saddle horn to the tips of the PMs. PM-annulus area: triangular area between the saddle horn and the tip of each PM. APM, Anterior papillary muscle; PPM, posterior papillary muscle; $P M$, papillary muscle. 
Laboratory Animals, created by the Institute of Laboratory Animal Resources, National Research Council, and published by the National Academy Press (revised, 1996).

\section{Statistical Analysis}

All statistical analyses were carried out using StatView software version 5.0 (Abacus Concepts Inc, Berkeley, Calif). The data were expressed as the mean \pm 1 standard error of the mean, and the different conditions were compared by performing the Wilcoxon signed-rank test.

\section{Results}

The CPB time was $42 \pm 3.5$ minutes, and the aortic crossclamp time was $21 \pm 1.2$ minutes. For all animals, necropsy confirmed that the secondary chordae had successfully been severed without any damage to the primary chordae, anterior mitral leaflet (AML), or aortic valve. Color Doppler echocardiography revealed no significant MR in any of the states.

\section{Left Ventricular Function and Volume}

Table 1 summarizes the LV function and volume data obtained in the post-CPB, CT- $1, \mathrm{CC}$, and CT-2 states. In the CT-1 state, the LVEF, PRSW, and Ees, which are the parameters for determining the LV systolic function, improved markedly compared with the values in the CC state. Similarly, in the CT-2 state, the LVEF, PRSW, and Ees improved markedly compared with these values in the CC state. No data were significantly different between the CT-1 and CT-2 states.

Tau and $\mathrm{dP} / \mathrm{dt}_{\min }$, which are the parameters for determining the LV diastolic function, improved in the CT-1 state when compared with the CC state; however, these parameters were not significantly improved in the CT-2 state when compared with the CC state.
Both the LV end-systolic and end-diastolic volumes decreased significantly in the CT-1 state when compared with the CC state. Similarly, both these parameters decreased significantly in the CT-2 state when compared with the CC state.

\section{Echocardiography}

Table 2 summarizes the echocardiographic data regarding the geometry of the mitral valve leaflet in the post-CPB, CT-1, $\mathrm{CC}$, and CT-2 states. All 3D echocardiography data revealed no significant difference between the CT-1 and CT-2 states. Compared with the $\mathrm{CC}$ state, the mitral valve tethering volume was lower (ie, better) in the CT-1 and CT-2 states. The posterior mitral leaflet (PML) tethering area improved in both CT-1 and CT-2 states when compared with the CC state, and this improvement was greater than that in the AML tethering area.

Table 3 summarizes the echocardiographic data regarding the geometry of the mitral annulus and PMs in the post-CPB, CT-1, CC, and CT-2 states. With regard to the mitral annular geometry, the S-L and C-C dimensions, annular area, and annular circumference (Figure 2) did not differ among the states.

During traction of the artificial chordae in the taut condition between the tip of the posterior PM and the anterior midseptal annulus (saddle horn) for CT, the posterior PMannulus distance was significantly shorter in the CT-1 and CT-2 states than in the CC state. Furthermore, during traction of the artificial chordae in the taut condition between the tip of the anterior PM and the anterior saddle horn, the anterior PM-annulus distance was slightly shorter in the CT-1 and CT-2 states than in the CC state.

The geometry between the mitral annulus and the PMs, PM-annulus area, and interpapillary angle did not differ among the states. However, the PM distance tended to be

TABLE 1. Hemodynamics

\begin{tabular}{|c|c|c|c|c|}
\hline Group & Post-CPB & CT-1 & CC & CT-2 \\
\hline$H R\left(\min ^{-1}\right)$ & $148 \pm 3.1$ & $150 \pm 5.8$ & $159 \pm 5.1^{\mathrm{a}}$ & $150 \pm 4.2^{d}$ \\
\hline LVEF (\%) & $46.3 \pm 3.6$ & $42.6 \pm 2.9^{d}$ & $33.2 \pm 2.3^{b}$ & $41.7 \pm 3.0^{d}$ \\
\hline LVESP $(\mathrm{mm} \mathrm{Hg})$ & $94.3 \pm 3.8$ & $85.6 \pm 2.7$ & $84.7 \pm 3.1$ & $86.3 \pm 1.4$ \\
\hline LVEDP $(\mathrm{mm} \mathrm{Hg})$ & $11.8 \pm 0.8$ & $12.7 \pm 0.8$ & $11.9 \pm 0.7$ & $12.5 \pm 1.3$ \\
\hline LVESV (mL) & $13.1 \pm 2.0$ & $17.2 \pm 1.7^{\mathrm{b}, \mathrm{d}}$ & $24.8 \pm 2.2^{b}$ & $17.1 \pm 1.7^{\mathrm{a}, \mathrm{d}}$ \\
\hline LVEDV $(\mathrm{mL})$ & $20.8 \pm 1.8$ & $27.4 \pm 1.7^{\mathrm{b}, \mathrm{d}}$ & $35.8 \pm 2.0^{b}$ & $26.9 \pm 1.6^{\mathrm{b}, \mathrm{d}}$ \\
\hline $\mathrm{dP} / \mathrm{dt} \max (\mathrm{mm} \mathrm{Hg} / \mathrm{s})$ & $1439.3 \pm 98.2$ & $1533.3 \pm 52.0$ & $1361.8 \pm 62.7$ & $1567.5 \pm 63.0$ \\
\hline $\mathrm{dP} / \mathrm{dt} \min (\mathrm{mm} \mathrm{Hg} / \mathrm{s})$ & $1533.8 \pm 89.2$ & $1397.1 \pm 44.4^{c}$ & $1281.1 \pm 68.0^{\mathrm{a}}$ & $1344.1 \pm 38.3$ \\
\hline Tau & $29.6 \pm 0.7$ & $27.5 \pm 0.7^{b, d}$ & $29.3 \pm 0.9$ & $28.5 \pm 0.8^{a}$ \\
\hline Ees $(\mathrm{mm} \mathrm{Hg} / \mathrm{mL})$ & $9.5 \pm 1.0$ & $6.7 \pm 0.5^{\mathrm{a}, \mathrm{d}}$ & $4.2 \pm 0.2^{b}$ & $6.7 \pm 0.3^{\mathrm{a}, \mathrm{d}}$ \\
\hline PRSW $(\mathrm{mm} \mathrm{Hg})$ & $51.3 \pm 5.9$ & $54.8 \pm 2.7^{\mathrm{d}}$ & $34.1 \pm 2.2^{b}$ & $59.2 \pm 3.5^{\mathrm{d}}$ \\
\hline
\end{tabular}

$H R$, Heart rate; $L V E F$, left ventricular ejection fraction; $L V E S P$, left ventricular end-systolic pressure; $L V E D P$, left ventricular end-diastolic pressure; $L V E S P$, left ventricular end-systolic volume; $L V E D V$, left ventricular end-diastolic volume; $d P / d t$ max, maximum positive rate of change of $L V$ pressure; $d P / d t$ min, minimum negative rate of change of LV pressure; Ees, end-systolic elastance; PRSW, preload recruitable stroke work; CPB, cardiopulmonary bypass; CT-1, state of traction of the artificial chordae simulated CT; $C C$, state of release of the artificial chordae represented chordal cutting; $C T$-2, state of traction of the artificial chordae simulated CT after CC state. ${ }^{\mathrm{a}} P<.05 .{ }^{\mathrm{b}} P<.001$ versus post-CPB. ${ }^{\mathrm{c}} P<.05 .{ }^{\mathrm{d}} P<.001$ versus CC. Data are expressed as mean \pm standard error. 
TABLE 2. Geometry of mitral valve leaflet

\begin{tabular}{ccccc}
\hline Group & Post-CPB & CT-1 & CC & CT-2 \\
\hline $\begin{array}{c}\text { Tethering } \\
\text { volume }\left(\mathrm{mm}^{3}\right)\end{array}$ & $748 \pm 92$ & $994 \pm 66^{\mathrm{b}, \mathrm{c}}$ & $1213 \pm 41^{\mathrm{a}}$ & $812 \pm 88^{\mathrm{c}}$ \\
$\begin{array}{c}\text { AML tethering } \\
\text { area }\left(\mathrm{mm}^{2}\right)\end{array}$ & $16.6 \pm 0.7$ & $41.0 \pm 0.7^{\mathrm{b}, \mathrm{c}}$ & $46.1 \pm 1.3^{\mathrm{b}}$ & $37.0 \pm 1.1^{\mathrm{b}, \mathrm{d}}$ \\
$\begin{array}{c}\text { PML tethering } \\
\text { area (mm }\end{array}$ & $8.4 \pm 0.6$ & $15.7 \pm 0.7^{\mathrm{b}, \mathrm{d}}$ & $25.1 \pm 1.2^{\mathrm{b}}$ & $15.0 \pm 0.7^{\mathrm{b}, \mathrm{d}}$ \\
$\begin{array}{c}\text { Tethering } \\
\text { depth (mm) }\end{array}$ & $3.5 \pm 0.1$ & $5.7 \pm 0.0^{\mathrm{b}, \mathrm{d}}$ & $6.0 \pm 0.1^{\mathrm{b}}$ & $5.4 \pm 0.1^{\mathrm{b}, \mathrm{d}}$ \\
\end{tabular}

$C P B$, Cardiopulmonary bypass; $A M L$, anterior mitral leaflet; $P M L$, posterior mitral leaflet; $C T-1$, state of traction of the artificial chordae simulated CT; $C C$, state of release of the artificial chordae represented chordal cutting; CT-2, state of traction of the artificial chordae simulated CT after CC state. Tethering volume indicates volume enclosed by the mitral annulus plane and 2 leaflets. AML tethering area: triangular area between anterior leaflet and annular plane in 4-chamber view of echocardiography. PML tethering area: triangular area between posterior leaflet and annular plane in 4-chamber view of echocardiography tethering depth; length between annular plane and coaptation point of leaflets in 4-chamber view of echocardiography. ${ }^{\mathrm{a}} P<.05 .{ }^{\mathrm{b}} P<.001$ versus post-CPB. ${ }^{\mathrm{c}} P<.05 .{ }^{\mathrm{d}} P<.001$ versus CC. Data are expressed as mean \pm standard error.

shorter in the CT- 1 and CT-2 states when compared with the CC state.

\section{Discussion}

\section{Key Findings}

In the present study, we evaluated the efficacy of CT procedure in a canine model of acute IMR by using 3D echocardiography. We obtained any key findings in this study. First, CT ameliorated tethering of the PML and AML; this was not observed when performing CC alone (Figure 3). Second, CT was associated with the recovery of valvular-ventricular continuity that was lost with CC and with improved LV systolic function.

\section{Amelioration of Posterior Mitral Leaflet Tethering}

CT significantly improved (ie, reduced) the tethering of both mitral leaflets, that is, the PML and AML. To the best of our knowledge, this is the first study to demonstrate the amelioration of PML tethering without maneuvering the posterior leaflet during surgical treatment of IMR. CT reduced the PML tethering probably because the maneuver pulled the tips of both PMs not only toward the annulus but also toward the anterior direction, which is physiologic. In our previous report, we proposed that augmented and progressive tethering of the PML may cause residual/recurrent IMR after simple mitral annuloplasty. ${ }^{15,16}$ In an experimental study, septal-lateral mitral annular reduction by mitral annuloplasty led to increased apical tethering of the posterior leaflet. ${ }^{17}$ Langer and colleagues ${ }^{18}$ observed that PML tethering accompanied IMR, and they attempted patch extension of the PML for mitral valve repair. This method could decrease PML tethering; however, the effect was at the cost of the LV dimensions and, consequently, functions. Otsuji and colleagues ${ }^{19}$ ameliorated PML tethering while maintaining the normal LV dimensions (ie, the distance between the PM tips and the midseptal mitral annulus), but by means of LV aneurysmectomy. Thus, CT may be a more physiologically effective technique for treating IMR caused by PML tethering.

\section{Mitral Annular Geometry}

In the present study, the mitral annular geometry remained unchanged despite the stitching of the saddle horn during CT. This result was expected because CT maintains the valvular-ventricular continuity; the artificial chordae function as the secondary chordae, which cause physiologic tension around the midseptal annulus, thus simulating the natural condition. Annular deformities may influence the coaptation of the mitral-valve leaflets, and our findings suggest that CT

TABLE 3. Geometry of annulus and papillary muscle

\begin{tabular}{|c|c|c|c|c|}
\hline Group & Post-CPB & CT-1 & CC & CT-2 \\
\hline Annular area $\left(\mathrm{cm}^{2}\right)$ & $3.7 \pm 0.3$ & $3.9 \pm 0.8$ & $4.4 \pm 0.2$ & $4.3 \pm 0.2$ \\
\hline Annular circumference $(\mathrm{cm})$ & $6.9 \pm 0.3$ & $7.1 \pm 0.3$ & $7.6 \pm 0.2$ & $7.5 \pm 0.2$ \\
\hline S-L dimension $(\mathrm{cm})$ & $2.1 \pm 0.1$ & $2.1 \pm 0.1$ & $2.3 \pm 0.1$ & $2.2 \pm 0.1$ \\
\hline C-C dimension $(\mathrm{cm})$ & $2.2 \pm 0.1$ & $2.3 \pm 0.2$ & $2.4 \pm 0.1$ & $2.4 \pm 0.1$ \\
\hline PM-annulus area $\left(\mathrm{cm}^{2}\right)$ & $2.1 \pm 0.1$ & $2.2 \pm 0.2$ & $2.7 \pm 0.3^{b}$ & $2.3 \pm 0.2$ \\
\hline Interpapillary angle (degrees) & $24.5 \pm 3.0$ & $25.7 \pm 2.4$ & $27.3 \pm 1.0$ & $27.2 \pm 1.7$ \\
\hline Anterior PM-annulus distance $(\mathrm{cm})$ & $3.2 \pm 0.1$ & $3.1 \pm 0.1$ & $3.4 \pm 0.2$ & $3.0 \pm 0.1$ \\
\hline Posterior PM-annulus distance $(\mathrm{cm})$ & $3.2 \pm 0.1$ & $3.2 \pm 0.1^{d}$ & $3.5 \pm 0.1^{\mathrm{a}}$ & $3.1 \pm 0.1^{\mathrm{c}}$ \\
\hline PM distance $(\mathrm{cm})$ & $1.3 \pm 0.1$ & $1.4 \pm 0.1^{d}$ & $1.7 \pm 0.1$ & $1.5 \pm 0.1$ \\
\hline
\end{tabular}

$C P B$, Cardiopulmonary bypass; $C T-1$, state of traction of the artificial chordae simulated $C T ; C C$, state of release of the artificial chordae represented chordal cutting; CT-2, state of traction of the artificial chordae simulated CT after CC state; PM, papillary muscle. Annular area indicates area of mitral annulus; annular circumference indicates mitral annular circumference; $\mathrm{S}$ - $\mathrm{L}$ dimension is the distance between septal and lateral site in mitral annulus; $\mathrm{C}-\mathrm{C}$ dimension is the distance between commeasures in mitral annulus; PM annulus area is the triangular area between saddle horn and each tip of the PM; interpapillary angle is made of 2 lines connecting saddle horn to tips of PM; anterior PM-annulus distance is the distance between the tip of the anterior PM and the anterior midseptal annulus; posterior PM-annulus distance is the distance between the tip of the posterior PM and the anterior midseptal annulus; PM distance; distance between tips of PM.

${ }^{\mathrm{a}} P<.05 .{ }^{\mathrm{b}} \mathrm{P}<.001$ versus post-CPB. ${ }^{\mathrm{c}} P<.05 .{ }^{\mathrm{d}} P<.001$ versus $\mathrm{CC}$. Data are expressed as mean \pm standard error. 

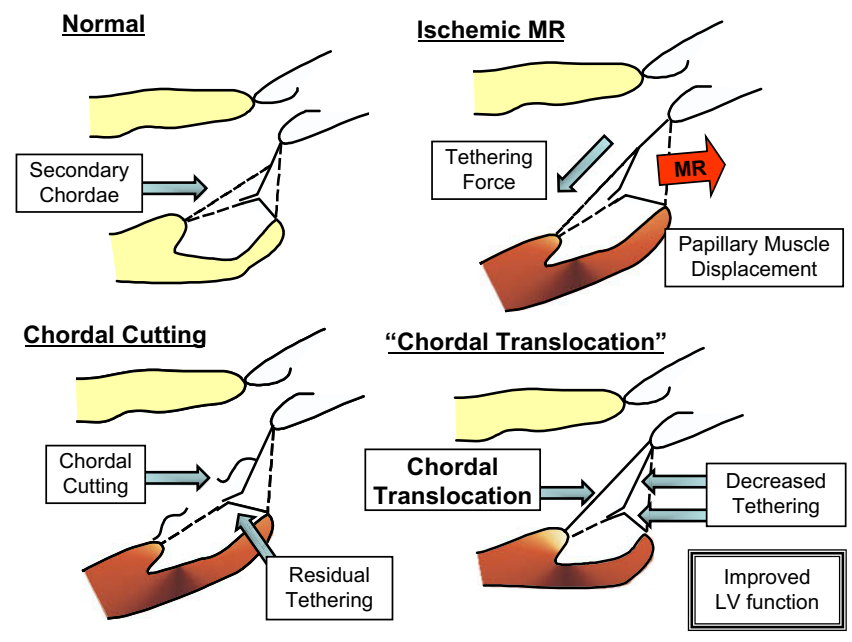

Figure 3. Leaflet tethering of the AML and PML occurred as the result of displacement of the PMs toward the lateral site (upper right). AML tethering was reduced after the cutting of the secondary chordae, whereas PML tethering remained unchanged (lower left). Tethering of the PML and AML was reduced after CT (right lower). $M R$, Mitral regurgitation; $L V$, left ventricular.

does not increase the risk of developing MR. The result may be important from the viewpoint of safety when CT is applied in patients. However, this canine model may not completely reflect clinical situations because this acute ischemic model showed less LV remodeling than has been observed in clinical situations. Ovine IMR model is appropriate for the evaluation of the chronic phase of IMR, and examination of the dilatation of the mitral annulus is a future research topic.

\section{Improvement of Left Ventricular Function}

The LVEF, PRSW, and Ees, which are parameters for determining the LV systolic function, improved in the CT state when compared with the CC state. Although the LV dimensions increased because of acute ischemia in the posterior and lateral LV walls, these dimensions improved with CT. Thus, CT can either improve or maintain LV function. We previously demonstrated that excessive tension around the PMs can lead to LV dysfunction. ${ }^{12,20}$ In the present study, the length of and tension in the artificial chordae used in CT were determined to be optimum in the taut condition. Komeda and colleagues ${ }^{21}$ reported that the taut traction force applied to the PMs was most effective.

$\mathrm{Tau}$ and $\mathrm{dP} / \mathrm{dt}_{\min }$, which are the parameters for determining LV diastolic function, improved in the CT-1 state when compared with the $\mathrm{CC}$ state; however, a significant difference is not seen in CT-2 but they improved in CT-1 compared with $\mathrm{CC}$ for Tau and $\mathrm{dP} / \mathrm{dt}_{\min }$ as said. The tendency of improvement by $\mathrm{CT}$ is indicated by the statistical difference in the CC of CT-1 and CT-2 between Tau and dP/dtmin. We be- lieve that the difference can be overcome by increasing the number of measurements.

\section{Previous Reports on Papillary Muscle Repositioning} Previously, several subvalvular techniques for leaflet-tethering repair have been reported; these techniques aimed at posterior papillary muscle (PPM) displacement. Internal repositioning of the PMs has been introduced for treating IMR. Kron and colleagues ${ }^{22}$ described the successful use of additional novel techniques in clinical studies. In their intriguing report, they indicated the efficacy of direct internal repositioning of PMs that were displaced because of the presence of a subvalvular transventricular suture between the tips of the PMs and the right fibrous trigone in the mitral annulus. Langer and colleagues ${ }^{23}$ evaluated the effects of direct internal repositioning of the PPM (ie, the technique reported by Kron and colleagues ${ }^{22}$ ) in an acute ovine model. They clinically evaluated the efficacy of direct internal repositioning of the PPM toward the saddle horn by using the aortic approach. ${ }^{24}$ These studies were based on the report of Tibayan and colleagues, ${ }^{25}$ which proposed that treatment for IMR should address the lateral displacement of the PPM. The above-mentioned technique of internal repositioning may be effective in singularly eliminating MR; however, excessive tension may develop in the PM because of the presence of internal-repositioning stitches. Our previous study demonstrated that excessive tension in the PMs leads to LV dysfunction in the canine heart. ${ }^{12}$ The use of CT for PM repositioning intended for $\mathrm{LV}$ restoration is unsuitable. It is thought that it is insufficient only in PM repositioning to improve remodeling of $\mathrm{LV}$ wall but is appropriate with methods such as the Acorn Cardiac Support Device (Acorn Cardiovascular, St Paul, Minn) and Corpsys device. The Acorn Cardiac Support Device has been reported to improve LV displacement and expansion during the 3-year follow-up of 300 clinical heart failure cases. ${ }^{26}$ Moreover, the use of the Coapsys device (Myocor Inc, Maple Grove, Minn) for functional mitral regurgitation (FMR) in RESTOR-MV was reported to improve MR in 19 clinical cases. ${ }^{27}$

In the CT method, artificial chordae are connected to the midseptal annulus by mimicking the natural force direction of the secondary chordae. The secondary chordae arising from each PM tip are connected to the middle region of the anterior leaflet, and the force is directed toward the midseptal annulus via the thickened portion of the anterior leaflet. In other words, the force direction in CT is almost identical to that in the natural physiologic state.

\section{Effects of Chordal Cutting}

$\mathrm{CC}$ has been reported to decrease mitral leaflet tethering and improve IMR; however, it might lead to a decrease in LV function because of the loss of ventricular-valvular continuity. In addition, the efficacy of CC in treating IMR is controversial. 
Messas and colleagues ${ }^{9}$ reported that LV function was maintained by $\mathrm{CC}$ in a normal ovine model and that MR improved after CC in a chronic ovine IMR model. ${ }^{10}$ In contrast, Rodriguez and colleagues ${ }^{28}$ indicated that $\mathrm{LV}$ function worsened after CC in an acute ovine IMR model because of the decrease in PRSW. They also observed that the CC group did not show a significant effect against MR when compared with the non-CC group. Borger and colleagues ${ }^{29}$ presented the 2-year follow-up findings to assess the efficacy of CC in IMR; they observed that CC does not affect LV function, compared with the non-CC group, and that $\mathrm{CC}$ leads to the prevention of MR recurrence.

\section{Canine Acute Ischemic Mitral Regurgitation Model}

For IMR experiments, several kinds of animal IMR models are used. In this study, we chose a canine acute IMR model. The anatomy of the mitral apparatus does not differ significantly between the dog and human. In particular, the point of attachment of the secondary chordae in the anterior leaflet and position of the PM and location of the stress line (ie, the line between the chordal attachment and anterior saddle horn) on the anterior leaflet are not different. In clinical IMR, LV wall infarction leads to LV remodeling; consequently, the PM is dislocated laterally. The mitral leaflet is also pulled through the secondary chordae laterally; this causes IMR. The canine acute IMR model simulates only the acute state and not the chronic state. However, the underlying mechanism and geometric change in the LV in IMR between experimental and clinical situations are similar. However, our IMR model differs from clinical IMR in 1 respect: Mitral annular dilatation is believed to be one of the causes of IMR. In our canine acute IMR model, the mitral annulus tended to dilate, but not significantly.

In this experiment, MR did not appear after LV ischemia because all the data were measured at the $\mathrm{CC}$ stage. We selected this method because our experiment showed the effectiveness of $\mathrm{CT}$ as an additional technique to CC. We used the previously reported canine acute IMR model. ${ }^{13} \mathrm{We}$ confirmed the development of acute IMR in 4 dogs. In these dogs, the left circumflex coronary artery was ligated without secondary CC; consequently, mild MR was noted after left circumflex coronary artery ligation. As mentioned above, we confirmed the usefulness of the canine acute IMR model in this experiment. Moreover, we have reported the effectiveness of CT with regard to LV function in a normal model. ${ }^{12} \mathrm{In}$ the present study, the LV function and changing geometry were evaluated using the canine acute IMR model based on the result of our previous report. It is believed that the chronic ovine IMR model is appropriate for the evaluation of chronic IMR.

\section{Clinical Implications}

CT ameliorates PML tethering and may contribute to a better prognosis in clinical settings. Therefore, CT may be a useful adjunct repair technique in combination with ring annuloplasty for treating IMR because the latter may aggravate postoperative PML tethering. ${ }^{15,16}$

Furthermore, because IMR is a ventricular disease (ie, not only a valvular disease), surgical ventricular restoration, if indicated, may be the first treatment preference. However, if this is not feasible, other techniques related to the LV geometry without damaging the LV should be considered. In addition, $\mathrm{LV}$ remodeling in the future should be carefully considered. CT may become a good choice because it ameliorates the severe tethering and prevents $L V$ remodeling without surgical ventricular restoration by maintaining valvular-ventricular continuity without the development of excessive tension toward the PMs (ie, a constant tethering index).

\section{Study Limitations}

This study poses several potential limitations. First, the data were obtained for canine hearts under acute IMR, open-chest, and open-pericardium conditions, immediately after a complex surgical procedure and cardiac arrest. To overcome the first limitation, we obtained CT data before and after the $\mathrm{CC}$, confirming the animal preparation was stable.

Second, we did not obtain the data as control. It might have been beneficial to use the $\mathrm{CC}$ group alone as the control for the evaluation of the effect of CT. However, we measured the changes after $\mathrm{CC}$ and after $\mathrm{CT}$ in the same individual because we believed that individual differences would be reduced with this method; moreover, we assumed that the effect of CT would be obvious with our previous method. ${ }^{12}$

\section{Conclusions}

Compared with CC alone, CT improved both the LV function and dimension in an animal model of IMR. In addition, the procedure ameliorated tethering of the PML and AML. Thus, CT may become an alternative surgical option for the treatment of IMR.

\section{References}

1. Ellis SG, Whitlow PL, Raymond RE, Schneider JP. Impact of mitral regurgitation on long-term survival after percutaneous coronary intervention. Am J Cardiol. 2002;89:315-8.

2. Grigioni F, Enriquez-Sarano M, Zehr KJ, Bailey KR, Tajik AJ. Ischemic mitral regurgitation: long-term outcome and prognostic implications with quantitative Doppler assessment. Circulation. 2001;103:1759-64.

3. Lamas GA, Mitchell GF, Flaker GC, Smith SC Jr, Gersh BJ, Basta L, et al. Clinical significance of mitral regurgitation after acute myocardial infarction. Survival and Ventricular Enlargement Investigators. Circulation. 1997;96:827-33.

4. Lam BK, Gillinov AM, Blackstone EH, Rajeswaran J, Yuh B, Bhudia SK, et al. Importance of moderate ischemic mitral regurgitation. Ann Thorac Surg. 2005;79:462-70.

5. Calafiore AM, Gallina S, Di Mauro M, Gaeta F, Iaco AL, D'Alessandro S, et al. Mitral valve procedure in dilated cardiomyopathy: repair or replacement? Ann Thorac Surg. 2001;71:1146-53.

6. Lachmann J, Shirani J, Plestis KA, Frater RW, LeJemtel TH. Mitral ring annuloplasty: an incomplete correction of functional mitral regurgitation associated with left ventricular remodeling. Curr Cardiol Rep. 2001;3: 241-6. 
7. Tahta SA, Oury JH, Maxwell JM, Hiro SP, Duran CM. Outcome after mitral valve repair for functional ischemic mitral regurgitation. J Heart Valve Dis. 2002;11:11-9.

8. Messas E, Guerrero JL, Handschumacher MD, Conrad C, Chow CM, Sullivan S, et al. Chordal cutting: a new therapeutic approach for ischemic mitral regurgitation. Circulation. 2001;104:1958-63.

9. Messas E, Yosefy C, Chaput M, Guerrero JL, Sullivan S, Menasche P, et al. Chordal cutting does not adversely affect left ventricle contractile function. Circulation. 2006;114(1 Suppl):I524-8.

10. Messas E, Pouzet B, Touchot B, Guerrero JL, Vlahakes GJ, Desnos M, et al. Efficacy of chordal cutting to relieve chronic persistent ischemic mitral regurgitation. Circulation. 2003;108(Suppl 1):II111-5.

11. Rodriguez F, Langer F, Harrington KB, Tibayan FA, Zasio MK, Cheng A, et al. Importance of mitral valve second-order chordae for left ventricular geometry, wall thickening mechanics, and global systolic function. Circulation. 2004;110(11 Suppl. 1):II115-22.

12. Fukuoka M, Nonaka M, Masuyama S, Shimamoto T, Tambara K, Yoshida H, et al. Chordal "translocation" for functional mitral regurgitation with severe valve tenting: an effort to preserve left ventricular structure and function. J Thorac Cardiovasc Surg. 2007;133:1004-11.

13. Otsuji Y, Handschumacher MD, Liel-Cohen N, Tanabe H, Jiang L, Schwammenthal E, et al. Mechanism of ischemic mitral regurgitation with segmental left ventricular dysfunction: three-dimensional echocardiographic studies in models of acute and chronic progressive regurgitation. J Am Coll Cardiol. 2001;37:641-8.

14. Watanabe N, Ogasawara Y, Yamaura Y, Yamamoto K, Wada N, Okahashi N, et al. Dynamics of mitral complex geometry and functional mitral regurgitation during heart failure treatment -real-time three-dimensional echocardiographic study. J Echocardiogr. 2006;4:51-8.

15. Kuwahara E, Otsuji Y, Iguro Y, Ueno T, Zhu F, Mizukami N, et al. Mechanism of recurrent/persistent ischemic/functional mitral regurgitation in the chronic phase after surgical annuloplasty: importance of augmented posterior leaflet tethering. Circulation. 2006;114(1 Suppl): I529-34.

16. Zhu F, Otsuji Y, Yotsumoto G, Yuasa T, Ueno T, Yu B, et al. Mechanism of persistent ischemic mitral regurgitation after annuloplasty: importance of augmented posterior mitral leaflet tethering. Circulation. 2005;112(9 Suppl):I396-401.

17. Timek TA, Lai DT, Tibayan F, Liang D, Rodriguez F, Daughters GT, et al. Annular versus subvalvular approaches to acute ischemic mitral regurgitation. Circulation. 2002;106(12 Suppl. 1):I27-32.

18. Langer F, Rodriguez F, Cheng A, Ortiz S, Nguyen TC, Zasio MK, et al. Posterior mitral leaflet extension: an adjunctive repair option for ischemic mitral regurgitation? J Thorac Cardiovasc Surg. 2006; 131:868-77.

19. Otsuji Y, Kuwahara E, Yuge K, Yotsumoto G, Ueno T, Nakashiki K, et al. Relation of aneurysmectomy in patients with advanced left ventricular remodeling to postoperative left ventricular filling pressure, redilatation with ischemic mitral regurgitation. Am J Cardiol. 2005;95: 517-21.

20. Komeda M, Shimamoto T. Cutting secondary chordae and placing dual taut stitches between anterior mitral fibrous annulus and heads each papillary muscle can treat ischemic mitral regurgitation without deteriorating left ventricular function. J Thorac Cardiovasc Surg. 2008;135: 226-7.

21. Komeda M, DeAnda A Jr, Glasson JR, Daughters GT, Bolger AF, Nikolic SD, et al. Improving methods of chordal-sparing mitral valve replacement-Part III: optimal direction for artificial chordae. J Heart Valve Dis. 1996;5:484-90.

22. Kron IL, Green GR, Cope JT. Surgical relocation of the posterior papillary muscle in chronic ischemic mitral regurgitation. Ann Thorac Surg. 2002;74:600-1.

23. Langer F, Rodriguez F, Ortiz S, Cheng A, Nguyen TC, Zasio MK, et al. Subvalvular repair: the key to repairing ischemic mitral regurgitation? Circulation. 2005;112(9 Suppl):I383-9.

24. Langer F, Schafers HJ. RING plus STRING: papillary muscle repositioning as an adjunctive repair technique for ischemic mitral regurgitation. J Thorac Cardiovasc Surg. 2007;133:247-9.

25. Tibayan FA, Rodriguez F, Zasio MK, Bailey L, Liang D, Daughters GT, et al. Geometric distortions of the mitral valvular-ventricular complex in chronic ischemic mitral regurgitation. Circulation. 2003;108(Suppl 1): II116-21.

26. Starling RC, Jessup M, Oh JK, Sabbah HN, Acker MA, Mann DL, et al. Sustained benefits of the CorCap Cardiac Support Device on left ventricular remodeling: three year follow-up results from the Acorn clinical trial. Ann Thorac Surg. 2007;84:1236-42.

27. Grossi EA, Saunders PC, Woo YJ, Gangahar DM, Laschinger JC, Kress DC, et al. Intraoperative effects of the Coapsys annuloplasty system in a randomized evaluation (RESTOR-MV) of functional ischemic mitral regurgitation. Ann Thorac Surg. 2005;80:1706-11.

28. Rodriguez F, Langer F, Harrington KB, Tibayan FA, Zasio MK, Liang D, et al. Cutting second-order chords does not prevent acute ischemic mitral regurgitation. Circulation. 2004;110(11 Suppl. 1):II91-7.

29. Borger MA, Murphy PM, Alam A, Fazel S, Maganti M, Armstrong S, et al. Initial results of the chordal-cutting operation for ischemic mitral regurgitation. J Thorac Cardiovasc Surg. 2007;133:1483-92. 